\title{
Anatomical structure and size of large intestinal mucosa in selected species of shrews and rodents
}

\author{
Bogdana WILCZYŃSKA
}

\begin{abstract}
Wilczyńska B. 1998. Anatomical structure and size of large intestinal mucosa in selected species of shrews and rodents. Acta Theriologica 43: 363-370.

The large intestine of eight Micromammalia species, of the orders Insectivora (Sorex minutus, Sorex araneus) and Rodentia (Sicista betulina, Clethrionomys glareolus, Microtus oeconomus, Apodemus flavicollis, Mus musculus, Cavia porcellus) were studied. Both the length and surface area of the mucosa of the alimentary canal are strongly associated with food hydration. In $M$. oeconomus, feeding exclusively on green parts of plants, the large intestine dominates the total length of the alimentary canal (35\% of length). In omnivorous S. betulina and A. flavicollis, the length of the large intestine is $30 \%$ of total length of the canal and only $20 \%$ in M. musculus fed with dry and granulated food. The large intestine of the rodents (but $S$. betulina) is divided into caecum, colon and rectum. The caecum is best developed in $M$. oeconomus, where the relative value of the caecum is $5.54 \mathrm{~mm} / \mathrm{g}$ and the surface area is $97.07 \mathrm{~mm}^{2} / \mathrm{g}$ of the body weight and least developed in $M$. musculus $-1.24 \mathrm{~mm} / \mathrm{g}$ and $13.34 \mathrm{~mm}^{2} / \mathrm{g}$. In insectivorous shrews, the large intestine is very short and non-differentiated into segments. Its proportion in the length of the alimentary canal amounts only to $6.5 \%$. The relative value of the length of the large intestine is between $1.34 \mathrm{~mm} / \mathrm{g}$ of body weight ( $S$. araneus) and $2.01 \mathrm{~mm} / \mathrm{g}$ ( $S$. minutus).
\end{abstract}

Department of Zoology of Vertebrates, Institute of Biology and Environment Protection, Nicholas Copernicus University, Gagarina 9, 87-100 Toruń, Poland, e-mail: wilczyn@biol.uni.torun.pl

Key words: anatomical structure, alimentary canal, large intestine, shrews, rodents

\section{Introduction}

The use of cellulose present in food is possible due to bacteria in the alimentary canal and demands special conditions, created in mammals by multi-chamber stomach or caecum (Dellow and Hume 1982, Barboza and Hume 1992, Osawa and Woodall 1992). Experiments on rats show that a plant diet causes lenghtening of large intestine whilst a meat diet causes its shortening (Dorożyńska et al. 1971, Radzikowska 1981). In the experiments carried out on Holochilus venezuelae and Zygodontomys microtinus, given varied amounts of cellulose in food (25-45\%), there was a direct relationship between the length growth of the caecum and the amount of cellulose in the diet (Dominiguez-Bello and Robinson 1991).

A majority of the morphometrical research on the alimentray canal presents only the lengths of parts of large intestine. To define the anatomical basis of 
functioning of the large intestine as an organ of cellulose digestion, water absorption, and the formation and temporal storage of faecal mass, it is vital to know the areas of the mucosa in particular parts of the large intestine.

I carried out the study on the large intestine of two wild-living species of Insectivora (Sorex minutus and Sorex araneus); four wild-living Rodentia (Sicista betulina, Clethrionomys glareolus, Microtus oeconomus, Apodemus flavicollis); and two laboratory rodents (Mus musculus and Cavia porcellus). These species represent different trophic types. The pygmy shrew and root vole are relative monophages, having carnivorous (Sorex minutus) and herbivorous (Microtus oeconomus) diets, respectively. The other species eat animal food ( $S$. araneus, $S$. betulina) and also eat seeds and fruit during blooming period. In the summertime, A. flavicollis and C. glareolus also feed on insects which make up 30-70\% of the diet (Obrtel 1973, 1974, Pernetta 1976, Holišova and Obrtel 1980, Pucek 1981). With laboratory animals, the lack of seasonal changes of food composition, with relation to their diversity with a possibility to choose, is frequently more limited than in natural environment. In its natural habitat, $M$. musculus is omnivorous (predominant grass seeds) and C. porcellus is herbivorous (grasses, herbs). In laboratory $M$. musculus and $C$. porcellus were fed with standard forage - for rodents.

\section{Material and methods}

The wild-living species (S. minutus, $S$. araneus, $S$. betulina, $C$. glareolus, $M$. oeconomus, and $A$. flavicollis) were captured between July and August $(1989-1992)$ in the Borki Forests $\left(53^{\circ} \mathrm{N}, 23^{\circ} \mathrm{E}\right.$, north-east of Poland), Mus musculus (albino form) and Cavia porcellus came from laboratory breeding. For each species, I studied the alimentary canals of ten adult males and ten adult females (non-pregnant and non-lactating).

The alimentary canals were fixed in 10\% neutralised formalin for 3-7 days. After rinsing and measuring the lengths of the alimentary canal (from the esophagus to the anus), the large intestine was cut. In rodents the large intestine is divided into three parts, ie caecum, colon and rectum. The division of the large intestine was made following Snipes (1982). Then, the lengths of the subsequent parts of the large intestine were measured. With use of the drawing apparatus, a distinguished fragment was projected from under the magnifying reading glass onto a sheet of paper and thus drawn. The length obtained this way was measured with the curvature apparatus and, after considering linear magnifying $(14 \times)$, the actual value of the part was calculated.

From the large intestine of shrews and from each part of the large intestine of rodents, I selected several millimeter-long sections at regular intervals $(1.5 \mathrm{~mm}$ for shrews and $6.0 \mathrm{~mm}$ for rodents).

The sections were processed using a standard paraffin method. I cut the blocks transversely into slices of $5 \mathrm{~m}$, which were then stained in Delafield's hematoxiline and eosin (HE) (Burck 1975). The sections were used to measure further (with magnification $250 \times$ in shrews and $15 \times$ in rodents) the external and internal circumferences of the consecutive slices. Multiplying average external circumference and internal one (the mean number of the series of measurements of consecutive slices) by the segment length, the external and internal areas of the large intestine were thus obtained.

The results of the measurements and calculations were then presented as mean numbers, giving standard average deviation. Significance of the differences was checked using Student's $t$-test, with $p$ $<0.05$ as statistically significant. 


\section{Results}

Anatomical structure of large intestine

The large intestine of Sorex araneus and Sorex minutus was non-differentiated (the lack of colon and caecum) and the shortest segment of the alimentary canal amounts to $6.5 \%$ of its length. But, in rodents the large intestine was very long and divided into the following parts (except in S. betulina where there was no colon): caecum, colon and rectum (Table 1)

The first part of the large intestine (caecum) in M. musculus and omnivorous species (S. betulina, A. flavicollis) reaches from $28.8 \pm 2.13 \mathrm{~mm}$ to $47.1 \pm 9.19 \mathrm{~mm}$, which is $5-10 \%$ of total alimentary canal length. In herbivorous root vole, the length is of $135.1 \pm 41.99 \mathrm{~mm}$ ( $22 \%$ of total length of the alimentary canal). Similarly, the external and internal diameters of the caecum reach the highest sizes in the herbivorous species of rodents. The size of the external diameter ranged from $4.9 \pm 0.47 \mathrm{~mm}$ ( $M$. oeconomus $)$ to $6.1 \pm 0.69 \mathrm{~mm}$ (C. glareolus) and the smallest external diameter in the northern-birch mouse (feeding on mixed food) does not exceed $2.0 \mathrm{~mm}$ (Table 1 ).

The colon reached length from $20.6 \pm 4.73 \mathrm{~mm}$ (M. musculus) to $174.9 \pm 21.71$ $\mathrm{mm}$ (C. porcellus), which is 4 and 6\% respectively of the length of alimentary canal.

The terminal, longest part of the large intestine was the rectum. In the northern-birch mouse and in the house mouse, the length of the rectum slightly exceeded $60.0 \mathrm{~mm}$ ( 20 and $11 \%$ respectively of canals length), in the common bank vole and root vole the length was over $150.0 \mathrm{~mm}$ and it was longest in the guinea pig $-616.7 \pm 125.37 \mathrm{~mm}$ ( $25 \%$ of total canals length). Within the large intestine, the rectum had the smallest internal and external diameters (Table 1).

The large intestines length makes up between 20\% (house mouse) to 53\% (root vole) of the total length of the alimentary canal of rodents. Figs 1 and 2 present the relative value of the alimentary canal length $(\mathrm{mm} / \mathrm{g})$ and its internal area $\left(\mathrm{mm}^{2} / \mathrm{g}\right)$.

\section{Structure of mucosa and its sizes}

In the large intestine of the studied species, a well-developed mucosa and submucosa created longitudinal folds. In each segment of the large intestine, both low and high folds (low folds are 0.5 of high folds) were distinguished. Their number and height differed in particular parts of the large intestine (Table 1).

The large intestine of the pygmy shrew had the largest number (6-9) of low folds and among rodents - in the caecum of the root vole (ca 8). The number of high folds was the largest in Cavia porcellus (12 - rectum) (Table 1). Microtus oeconomus represented a peculiarly-structured mucosa in the caecum and colon; here, besides low folds in caecum, there is a fold exceeding others in height by ten times $(2429.4 \pm 646.78 \mathrm{~m})(p \leq 0.05)$. The fold is slightly lower in colon $(1868.2 \pm 286.94 \mathrm{~m})$. There are other three folds in the colon and they reach from 612.5 to $943.3 \mathrm{~m}$. Low folds ( 4 of them) are from $269.5 \pm 28.43$ to $494.9 \pm 4.21 \mathrm{~m}$. 


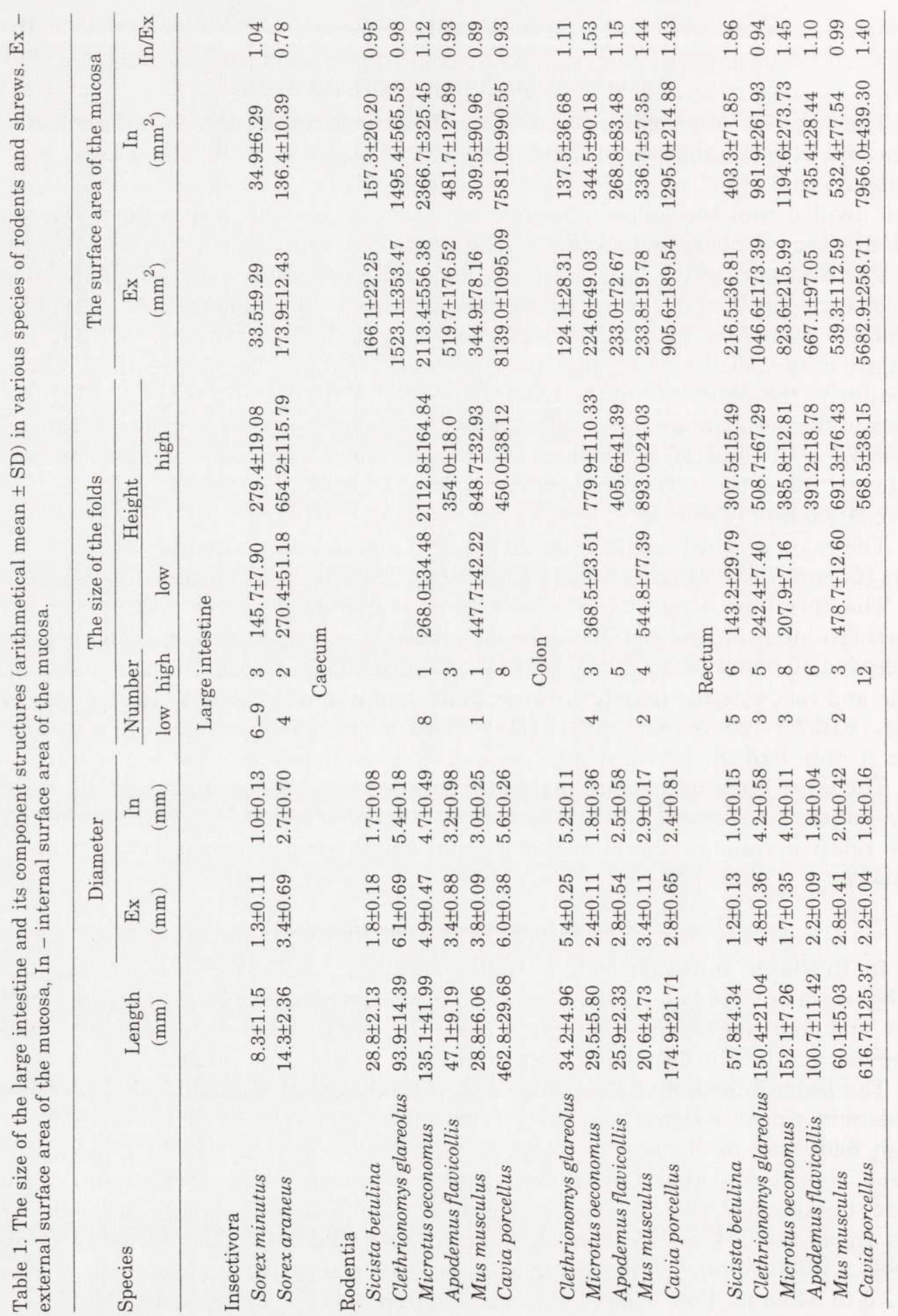


Because of the poor development of the mucosa area in the large intestine, its structures (longitudinal folds) slightly extended the sizes of the internal area. The coefficient of the development of the mucosa, expressed through a ratio of external area to internal area, reached 1:0.78 in the insectivorous (common shrew) and 1:1.04 (pygmy shrew); being higher in rodents, it reached 1:1.47 (max in northern-birch mouse).

The internal area of the caecum reached considerably high sizes in the herbivorous rodents. The realtive value $\left(\mathrm{mm}^{2} / \mathrm{g}\right.$ of body weight) in the internal

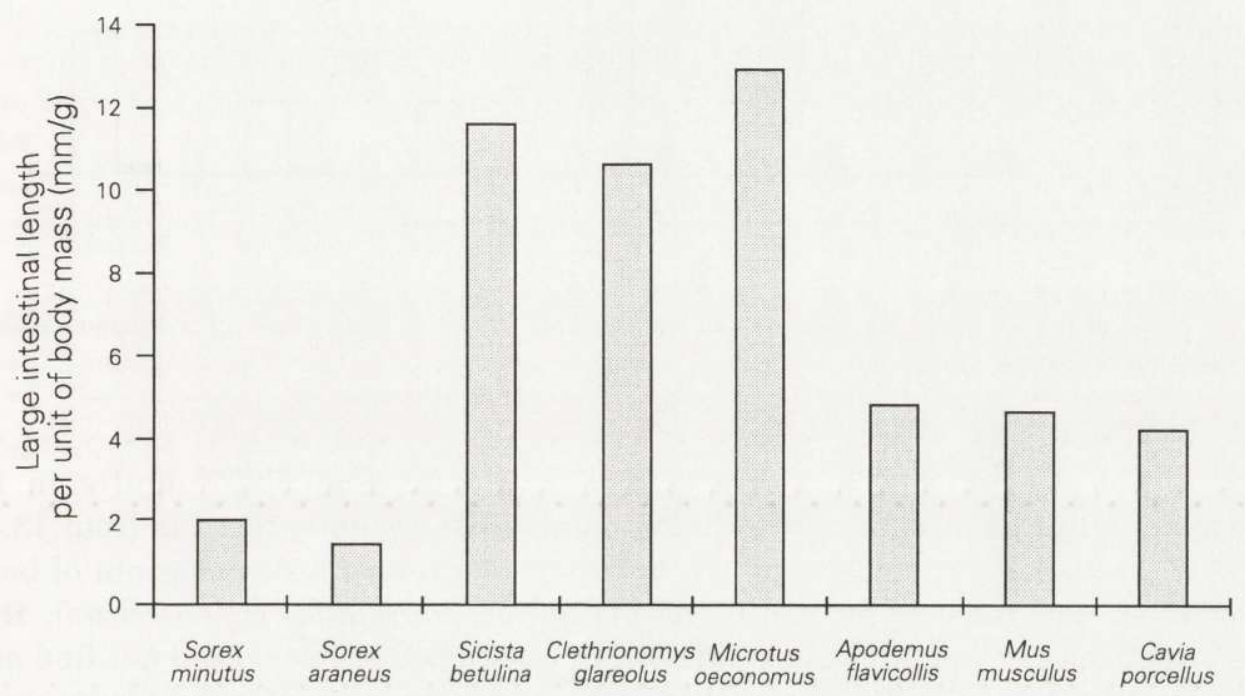

Fig. 1. Ratio of the large intestinal length $(\mathrm{mm})$ to body mass $(\mathrm{g})$ in various species of rodents and shrews.

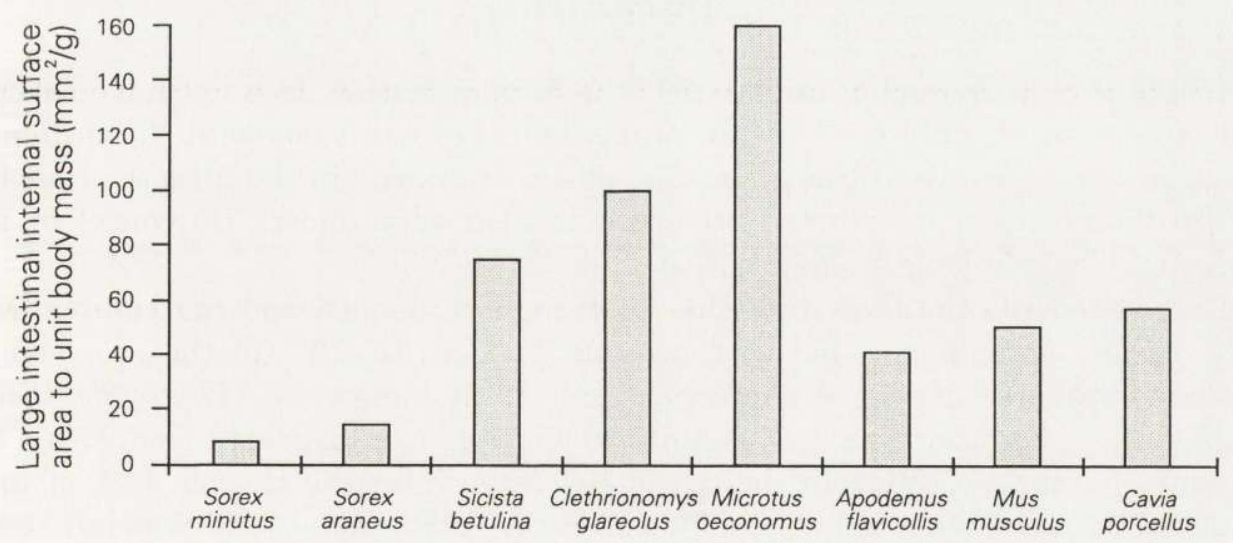

Fig. 2. Ratio of the large intestine internal surface area $\left(\mathrm{mm}^{2}\right)$ to body mass $(\mathrm{g})$ in various species of rodents and shrews. 


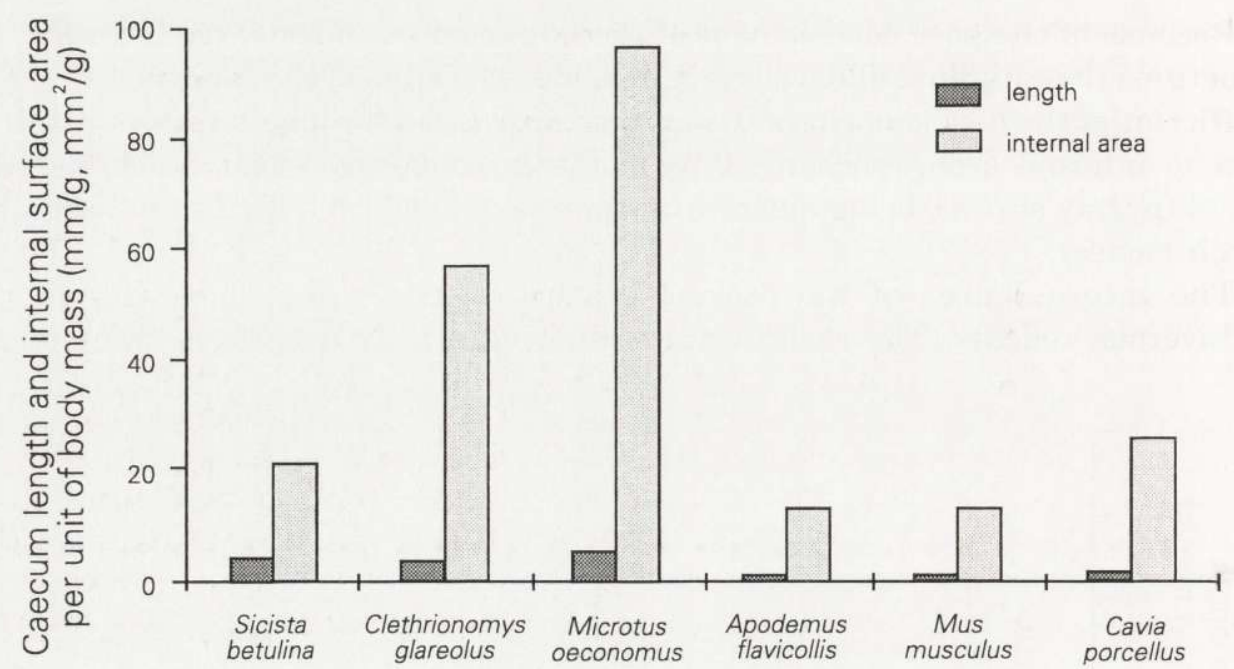

Fig. 3. Ratio of the caecum length $(\mathrm{mm})$ and surface area $\left(\mathrm{mm}^{2}\right)$ to body mass $(\mathrm{g})$ in various species of rodents and shrews.

area of the caecum is $57.27 \mathrm{~mm}^{2} / \mathrm{g}$ in C. glareolus and $97.07 \mathrm{~mm}^{2} / \mathrm{g}$ in $M$. eoconomus. In the caecum of wild-living omnivorous rodents, there is from 13.49 $\mathrm{mm}^{2}$ (A. flavicollis) to $21.06 \mathrm{~mm}^{2}$ (S. betulina) of internal area per gram of body weight. In the rodents fed with granulates (M. musculus, C. porcellus), this coefficient reaches similar values (Fig. 3). In all studied species, I did not find any significant statistical differences either in the length or external and internal areas of the large intestine between males and females.

\section{Discussion}

In the shrews living on animal diet, the large intestine does not have caecum and is very short, only $6.5 \%$ of the canals length. In this segment, formation of faecal pellets and water absorption take place. Similarly, in the insectivorous bat (Tadarida nigeriae), the large intestine is also very short, $7 \%(\max )$ of the alimentary canals length (Okon 1977).

But, in rodents the large intestine is strongly developed and contributes from $20 \%$ (in the house mouse fed with granulated food) to $53 \%$ (in the root vole, a typical herbivore) of the alimentary canal. With kangaroos (Thylogale thetis, Macropus eugenii and Macropus giganteus) which live on hydrated food with a big amount of cellulose, the total length of the large intestine is over $43 \%$ of total length of the alimentary canal (Dellow and Hume 1982, Osawa and Woodall 1992). In the herbivorous root vole living on plant diet caecum is a very large part (43\%) of the large intestine In the South-American voles, Holochilus venezuelae and 
Zygodontomys microtinus, Dominguez-Bello and Robinson (1991) showed directly a proportional relationship between the length of the caecum and the mass of given cellulose in the diet.

Plant food, unlike animal food, is not rich in calories and needs more time to be digested; access to it varies throughout the year in moderate climate and is usually very hydrated (green parts of plants). The herbivore show, therefore, the increased volume and area of the large intestine. In parts of the large intestine, the surface area of the mucosa is important in C. glareolus and $M$. oeconomus and reaches $57.27 \mathrm{~mm}^{2} / \mathrm{g}$ and $97.07 \mathrm{~mm}^{2} / \mathrm{g}$ respectively. Numerous high longitudinal folds affect the increase in the internal area of particular parts of the large intestine in the rodents. The presence of an extra fold in the root vole in the caecum and in the colon is connected with digesting cellulose. Taking into account the works of Bjorndal et al. (1990) on the phenomenon of cycotrophy in rodents and on the mechanisms called segregation of food in colon (Vorontsov 1967, Björnhag and Sjoblon 1977, Batzli and Cole 1979, Björnhag et. al. 1994), this may be significant in absorbing cellulose. Through bacterial concentration and re-directing of food by the fold from colon to caecum, each portion of food undergoes fermentation and absorption at least twice.

\section{References}

Barboza P. S. and Hume I. D. 1992. Hindgut fermentation in the wombats: two marsupial grazers. Journal of Comparative Physiology 162B: 561-566.

Batzli G. O. and Cole F. R. 1979. Nutritional ecology of microtine rodents: digestibility of forage. Journal of Mammalogy 60: 740-750.

Bjorndal K. A., Bolten A. B. and Moore J. E. 1990. Digestive fermentation in herbivores effect of food particle size. Physiological Zoology 63: 710-721.

Björnhag G., Becker G. Buchholz C. and von Engelhardt W. 1994. The gastrointestinal tract of the rock hyrax (Procavia habessinica) 1. Morphology and motility patterns of the tract. Comparative Biochemistry Physiology 109 A: 649-653.

Björnhag G. and Sjoblom L. 1977. Demonstration of coprophagy in some rodents. Sweden Journal of Agricultural Research 7: 105-113.

Burck H-C.1975. Technika histologiczna. PZWL, Warszawa: 1-234. [In Polish]

Dellow D. W. and Hume I. D. 1982. Studies on the nutrition of Macropodine Marsupials IV. Digestion in the stomach and the intestine of Macropus giganteus, Thylogale thetis and Macropus eugenii. Australian Journal of Zoology 30: 767-777.

Dominguez-Bello M. G. and Robinson M. D. 1991. A comparison of digestive adaptation in two neotropical cricetid rodents (Holochilus venezuelae and Zygodontomys microtinus). Physiological Zoology 64: 1542-1551.

Dorożyńska N., Cymborowski B. and Radzikowska M. 1971. [The effect of diet on the structure and function of the alimentary canal of the representatives of various animal groups]. Przegląd Zoologiczny 15: 40-45. [In Polish]

Holišova V. and Obrtel R. 1980. Food resource partitioning among four myomorph rodent populations coexisting in a spruce forest. Folia Zoologica 29: 193-207.

Obrtel R. 1973. Animal food of Apodemus flavicollis in a Lowland Forest. Zoologické Listy 22: 15-30. 
Obrtel R. 1974. Comparison of animal food eaten by Apodemus flavicollis and Clethrionomys glareolus in a Lowland Forest. Zoologické Listy 23: 35-46.

Okon E. E. 1977. Functional anatomy of the alimentary canal in the fruit bat (Eidolon helvum) and the insect bat (Tadarida nigeriae). Acta Zoologica (Stockholm) 58: 83-93.

Osawa R. and Woodall P. F. 1992. A comparative study of macroscopic and microscopic dimensions of the intestine in five macropods (Marsupialia: Macropodidae). II. Relationship with feeding habits and fibre content of the diet. Australian Journal of Zoology 40: 99-113.

Pernetta I. C. 1976. Diets of the shrews Sorex araneus L. and Sorex minutus L. in Wytham grassland. Journal of Animal Ecology 45: 899-912.

Pucek Z. 1981. Keys to vertebrates of Poland. Mammals. PWN - Polish Scientific Publisher, Warszawa, 1-376.

Radzikowska M. 1981. [The effect of different diet on the structure and the functioning of the alimentary canal of the rat (Rattus rattus L.)]. Przegląd Zoologiczny 25: 83-92. [In Polish with English summary]

Snipes R. L. 1982. Anatomy of the caecum of the Gerbil Meriones unguiculatus (Mammalia, Rodentia, Cricetidae). Zoomorphology 100: 189-202.

Vorontsov N. N. 1967. [Evolution of the alimentary system of myomorph rodents]. Nauka, Novosibirsk: 1-234. [In Russian]

Received 10 July 1997, accepted 12 October 1998. 